\title{
LA-5508-MS
}

INFORMAL REPORT

\section{Failure of Cooling Tower LOB-CT-1}


This report was prepared as an account of work sponsored by the United States Government. Neither the United States nor the United States Atomic Energy Commission, nor any of their employees, nor any of their contractors, subcontractors, or their employees, makes any warranty, express or implied, or assumes any legal liability or responsibility for the accuracy, completeness or usefulness of any information, apparatus, product or process disclosed, or represents that its use would not infringe privately owned rights.

In the interest of prompt distribution, this LAMS report was not edited by the Technical Information staff.

Printed in the United States of America. Available from National Technical Information Service

U. S. Department of Commerce 5285 Port Royal Road

Springfield, Virginia 22151

Price: Printed Copy \$4.00; Microfiche $\$ 1.45$ 


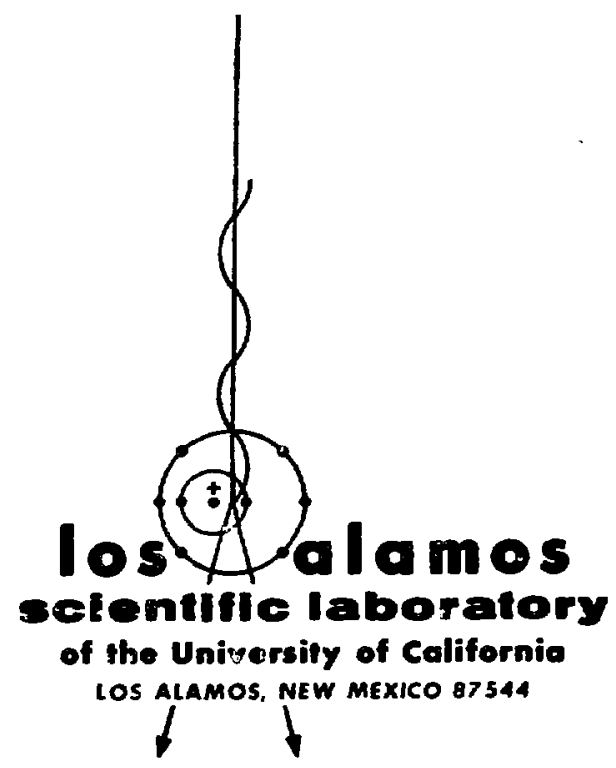

\title{
LA.5508-MS \\ informal Report \\ UC.38
}

REPORTING DATE: January 197

ISSUED: March 1974

\section{Failure of Cooling Tower LOB-CT-1}

by

\author{
W. S. Midkiff
}

NOTICE

This report was prepared as an account of work report was pred States Government. Neither spon United States Atomic Energy the Unied star employees, nor any of Commission, not any of thactors, of their employees, their contractors, subcontractors, or ther

makes any warranty, express or implied, or assact

legal liability or responsibility for the accuracy, com

pleteness of usefulness of any information, apparatus,

product or process disclosed, or represents that its use

would not infringe privately owned rights. 


\title{
FAILURE OF COOLING TOWER LOB-CT-1
}

by

\author{
W. S. Midkiff
}

\begin{abstract}
Following the loss of cooling tower LOB-CT-1, an investigation was conducted to determine the cause and to develop precautions to prevent future cooling tower losses. This cooling tower, located in the office-building basement of the Clinton P. Anderson Los Alamos Meson Physics Facility (LAMPF), was shut down on October 29, 1973. Excessive use of chelate chemical was judged to be the major factor involved in the high corrosion rates observed. A number of precautions are listed which should prevent further 'surprise' corrosion problems. The precautions include precalculation of chemical additions, visual inspection, corrosion coupons, corrosion meters, and chemical analyses of operating conditions.
\end{abstract}

On October 29, 1973, the cooling tower LOB-CT-1, located in the basement of the office building of the Clinton P. Anderson Los Alamos Meson Physics Facility (LAMPF), was judged inoperative and shut down. An investigation to determine the cause and to develop precautions to prevent subsequent cooling tower losses was initiated. Various stages of the investigation were conducted between December 12, 1973 and December 21, 1973.

Apparently, the LOB-CT-1 was being treated during September, October, and November, 1971, with 20 to $100 \mathrm{mg} / \mathrm{l}$ (by weight)* concentrations of Phoenix 255 . Phoenix 255 contains the chelates EDTA, NTA, DTPA, and HEEDTA plus a ferrous and a nonferrous corrosion inhibitor and a dispersant. An alternate chemical, Phoenix 209, contains the same chelates but different corrosion inhibitors. Approximately 50\% of Phoenix 255 and 209 is responsive to the chelate test. A strike during this period resulted in improper operation of the cooling tower and silica scale was allowed to accumulate. The system was cleaned with ammonium bifluoride in early November.

\footnotetext{
" "by weight" as opposed to response to chelate test.
}

Following the bifiuoride treatment, the system was apparently operated satisfactorily until early August, 1972. Approximately $50 \mathrm{mg} / \ell$ (by weight) Phoenix 209 was maintained from November 15, 1971 until August 3, 1972. Test coupons indicated a maximum corrosion rate of 0.704 mils per year (mpy) for steel and $0.172 \mathrm{mpy}$ for copper.

Five to six weeks of operation without treatment followed.

On September 13, 1972, treatment with Phoenix 255 began. Average concentrations of chemical varied from 10 to $50 \mathrm{mg} / \ell$ (by weight). This treatment was followed until the system was shut down for the winter on November 1 , 1972. Test coupons indicated corrosion rates of $0.66 \mathrm{mpy}$ for steel and $3.90 \mathrm{mpy}$ for copper.

Upon start-up in May, Phoenix $\mathrm{Cu}$, a cleaning ria mical similar to Phoenix 255 but with less inhibitor, was utilized. This chemical remained in tine system from May 1, 1973 until June 11, 1973. Average concentrations of chemical varied from 100 to $300 \mathrm{mg} / \ell$ (by weight). Test coupons for the month of May indicated a corrosion rate of $66.57 \mathrm{mpy}$ for steel and $1.66 \mathrm{mpy}$ for copper. In mid-June, the treatment chemical was changed to Phoenix 
255. Average concentrations varied from 200 to $300 \mathrm{mg} / \mathrm{l}$ (by weight). Corrosion was st 1 present. Test coupons for June and July indicated corrosion rates of 20.2 and $\mathbf{3 2 . 8}$ mpy for steel and 1.34 and 1.27 mpy for copper, respectively.

By this time, the stock feed solution of chemical was being maintained at approximately 10 times the concentration necessary for proper treatment. Although the average concentrations calculated to be in the system do not appear to be highly corrosive, the author feels that concentrations fluctuated so much that highly corrosive conditions were intermittently present. The problem of fluctuating concentrations was accented during the period from August 8 - August 22, 1973, during which time in excess of $100 \mathrm{lb}$ of Phoenix 255 was put directly into the basin. This had the effect of localized $\mathrm{pH}$ values of 4 to 5 which are highly corrosive to steel as well as the cleaning effect of the chelate which constantly keeps the bare metal exposed. Tesi coupons for August and September have not yet been returned by Phoenix.

On December 12,1973, six weeks after it was reported inoperative, the cooling tower was disassembled and inspected with the following results:

(1) The inlet end of the header had been corroded completely through causing an opening of $180^{\circ}$ connecting the first two sprayers. Corrosion was from the inside out (Figs. 1 and 2 ).

(2) The steel nipple connecting to the header was badly corroded from the inside (Fig. 3 ).

(3) Corrosion appeared to be proportional to velocity. The inlet half of the header showed more extensive corrosion than the dead end (Fig. 4).

(4) Outer panels were excellent where protective paint remained. Where it was gone (clue to bifluoride treatment?) an oxide surface remained. Corrosion pits and "washes" appeared where splash or spray had been greatest (Fig. 5).

(5) Blower ducts had protective paint remaining in the less exposed areas. The tops and parts of sides exhibited an oxide surface with intermittent pits and "washes" of corrosion (Figs. 6 and 7).

(6) The fill had been reduced to "lace" by corrosion. Holes riddled the baffles from top to bottom. Corrosion was more extensive at the tops of the baffles where their surfaces were exposed to spray and splash. As the draining water formed a film over the lower portions of the baffles, corrosion rates were apparently reduced (Figs. 8 and 9).

(7) The pipe leading to the centrifugal pump was corroded on the inside.

(8) The ferrous nut and washers holding the pump impeller showed corrosion but the nonferrous pump and impeller showed no damage.

A sample of water was taken from the basin at the time it was disassembled. The water had been standing for approximately one month and was about double operating concentration. An atomic absorption analysis by Group $\mathrm{H-7}$ revealed the following concentrations:

$\begin{array}{lcc}\text { Calcium } & 24 & \mathrm{mg} / \mathrm{l} \\ \text { Magnesium } & 6.2 & \mathrm{mg} / \mathrm{l} \\ \text { Copper } & 0.12 \mathrm{mg} / \mathrm{l} \\ \text { Iron } & 119 & \mathrm{mg} / \ell \\ \text { Zinc } & 79 & \mathrm{mg} / \ell \\ \text { Alkalinity } & 250 & \mathrm{mg} / \ell \\ \text { pH } & 6.8 & \end{array}$

\section{CONCLUSION}

Excessive use of chelate chemical resulted in the high rates of corrosion. Of the four chelates used in Phoenix $\mathrm{Cu}$ and Phoenix 255, one or more was always present which to some extent was able to pull iron away from iron oxide. If this protective oxide layer is constantly being pulled from the parent metal, the bare surface is exposed to oxygen for further corrosion. As a result, corrosion rates were highest where the oxygen-warermetal interface was being renewed fastest, in the spray zone.

\section{RECOMMENDATIONS}

To prevent further corrosion or scale problems, the following precautions should be practiced.

(1) Operate cooling tower at recommended levels of chemical treatment.

(2) Calculate, by weight, quantities of chemical to be added. Weekly record checks of quantities of chemical added versus quantities of water used should confirm the precalculated concentrations.

(3) Facility should be provided for easy and routine visual inspection of the header-fill area.

(4) Routine (monthly) use of corrosion coupons and rapid analysis will supplement visual inspection. The capabiity of on-site analysis within two weeks following removal from the system should be investigated.

(5) Electrical measurement of corrosion rates should be investigated. Both resistance and linear polarization probes are commercially available and both allow rate of ccrrosion to be monitored. Test coupons provide only single point data for a corrosion rate assumed to be linear.

(6) At least weekly chemical analyses of the water system (including treated make-up water) should be made. The operator and supervisor should be aware of changes from the ordinary or other clues suggesting nonstandard operation. For example:

(a) Excessive chelate concentrations can give erroneous or even zero response to the chelate test. 
Dilutions may be required for accurate analyses.

(b) Excessive chelate can interfere with the hardness test giving low answers or rendering the test completely unresponsive.

(c) Excessive chelate can be responsible for stimulation of bacteria growth and increased chlorine demand.

Adherence to these precautions will remedy the cooling tower problems that have been most severe at LAMPF. The records indicate that LOB-CT-1 has been operated safely with more than one chemical treatment when recommended concentrations were maintained. Five possible precautions haye been outlined to insure safe operations. While satisfactory long-term operation relies ultimately on the sujtability of the chemical treatment recommended, at least three Phoenix chemicals have been demonstrated to be adequate at LASL when properly applied. Investigation and surveillance will continue in an effort to improve the selection and application of chemicals.

A detailed history of LOB-CT-1 follows.

\section{HISTORY - LOB-CT-1}

$\mathrm{SiO}_{3}$ deposits

Workers' strike

No scele

Steel $1.09 \mathrm{Cu} 0.027$

Steel $1.05 \mathrm{Cu} 0.294$

Coupons in excellent condition

Steel 0.555 Cu 0.014

Steel 0.509 Cu 0.172

Steel 0.704 Cu 0.111

\begin{tabular}{l}
\multicolumn{1}{c}{ Date } \\
\hline $9-1-71$ \\
$9-8-71$ \\
$9-15-71$ \\
$9-22-71$ \\
$9-29-71$ \\
$10-6-71$ \\
$10-14-71$ \\
$10-20-71$ \\
$11-4-71$
\end{tabular}

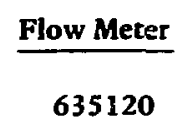

649850

672110

680480

688670

696140

706160

708770

719150

Bifluoride Treatment

11-15-71

11-17-71

11-23-71

12-27-71

1-13-72

1-24-72

2-2-72

2-14-72

2-22-72

2-28-72

3-6-72

3-15-72

3-21-72

3-24-72

4-3-72

4-12-72

4-26-72

5-19-72

5-23-72

5-26-72

5-30-72

6-5-72

6-7-72

6-12-72

6-16-72

6-19-72

6-20-72
$-727670$

729930

736820

774560

789050

798200

$-804030$

813830

821290

826970

833030

844890

Installed new pump (seal failure)

852840

861580

874600

892990

9099820

916820

922200

929270

-941180

944930

954010

963020

970820

974340
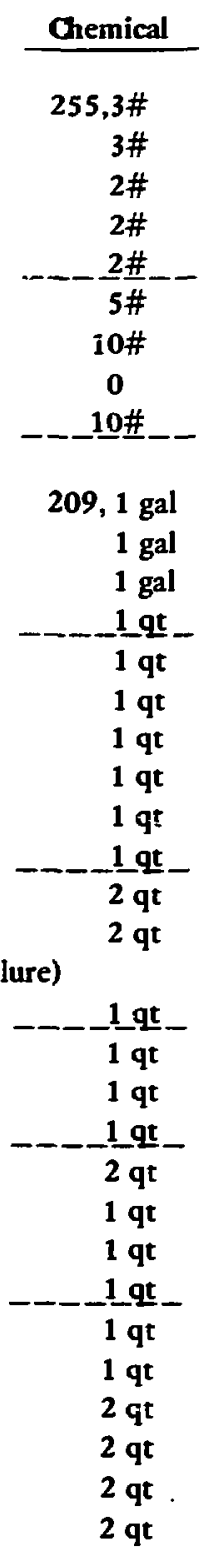

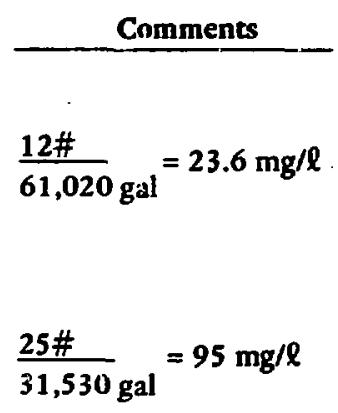

$\frac{3.25 \times 10.9}{61,380 \mathrm{gal}}=70 \mathrm{mg} / \mathrm{l}$

4 conc hardness

pH 8.5.9

$\frac{0.5 \times 10.9}{14,980 \mathrm{gal}}=43.5 \mathrm{mg} / \mathrm{l}$

$\frac{1 \times 10.9}{29,000}=45 \mathrm{mg} / \mathrm{l}$

$3^{1 / 2}$ conc hardness

$\frac{1.25 \times 10.9}{28,550}=57 \mathrm{mg} / \mathrm{l}$

$\frac{0.75 \times 10.9}{48,240}=20 \mathrm{mg} / \mathrm{l}$

3 conc hardness

$\frac{1.25}{24,360}=67 \mathrm{mg} / \mathrm{l}$

$\frac{4.5 \times 10.9}{80,430}=73 \mathrm{mg} / \mathrm{l}$

$21 / 2$ conc hardness 


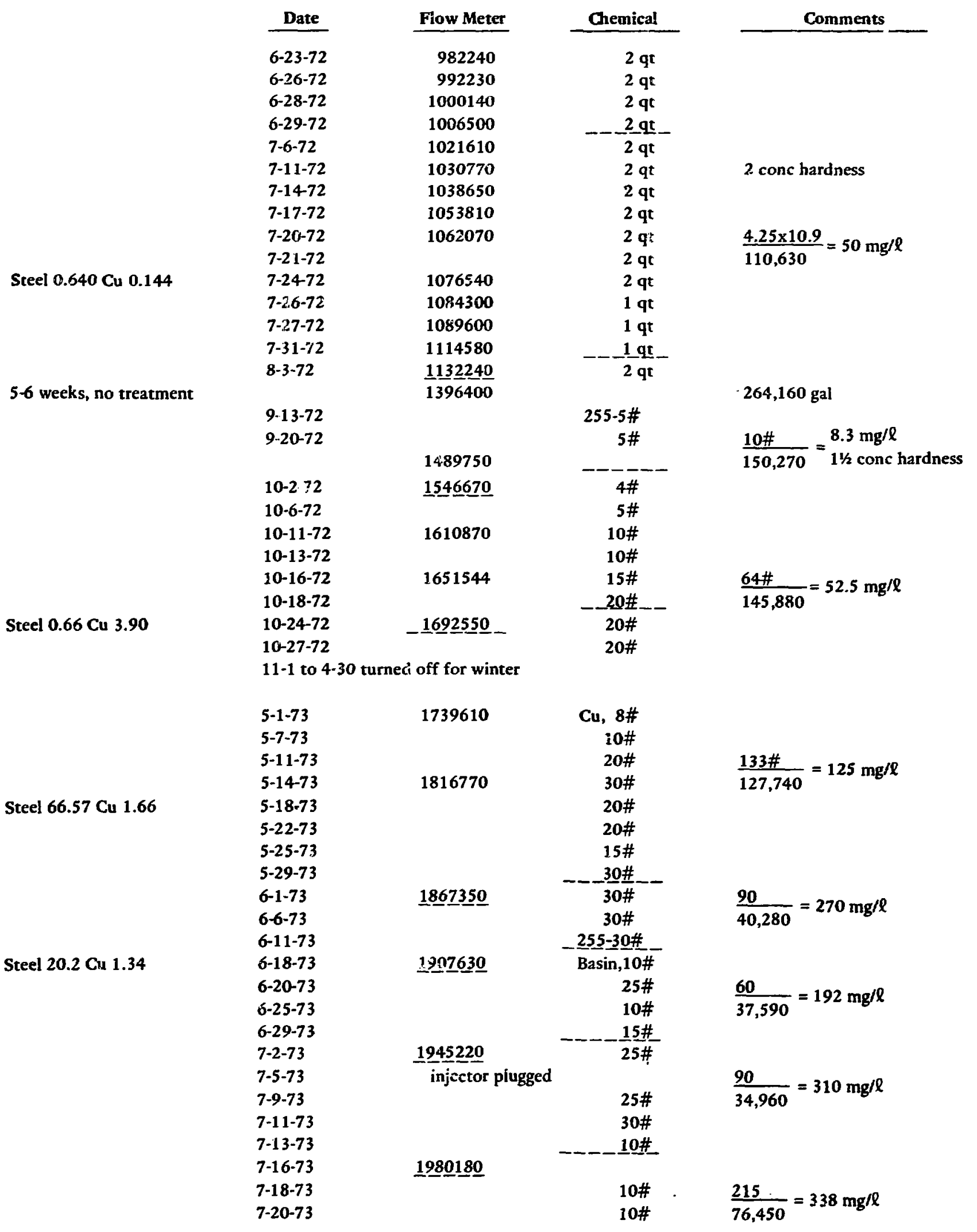


Steel $32.8 \mathrm{Cu} 1.27$

Steel showing high corrosion rates, copper OK

\begin{tabular}{|c|c|c|c|}
\hline Date & Flow Meter & Chemical & Comments \\
\hline $7-23-73$ & & $10 \#$ & \\
\hline $7-25=73$ & & $30 \#$ & \\
\hline $7-27-73$ & & 30\# & \\
\hline $7-30-73$ & & Basin 20\# & \\
\hline $8-1-73$ & & $30 \#$ & \\
\hline $8-3-73$ & & 25\# & \\
\hline $8-6-73$ & & 25 \# & \\
\hline $8-8-73$ & & - Basin 25 & \\
\hline $8-15-73$ & $205663 \underline{0}$ & Basin 20\# & \\
\hline $8-17-73$ & & $255,20 \#$ & in basin \\
\hline $8-20-73$ & & Basin 30\# & \\
\hline $8-22-73$ & & Basin 20\# & \\
\hline $8-29-73$ & & 12\# & $=195 \mathrm{mg} / \mathrm{\ell}$ \\
\hline $8 \cdot 31-73$ & & $12 \#$ & $\overline{123,180}=190 \mathrm{mg} / \mathrm{t}$ \\
\hline $9-4-73$ & 2129850 & $15 \#$ & \\
\hline $9-7-73$ & & $30 \#$ & \\
\hline $9-10-73$ & & Basin 1n\# & \\
\hline $9-12-73$ & & $15 \#$ & \\
\hline $9-17-73$ & & $15 \#$ & \\
\hline $9-19-73$ & $\underline{2179810}$ & $10 \#$ & \\
\hline $9.21-73$ & & $10 \#$ & \\
\hline $9-24-73$ & & $15 \#$ & \\
\hline $9-28-73$ & & 10\# & + 6\#basin \\
\hline $10-3-73$ & & $20 \#$ & \\
\hline $10-9-73$ & & $20 \#$ & $=150 \mathrm{mg} / \mathrm{Q}$ \\
\hline $10-11-73$ & & $20 \#$ & 142,780 \\
\hline $10-17-73$ & & $12 \#$ & \\
\hline $10-19-73$ & & $12 \#$ & \\
\hline $10-23-73$ & & $20 \#$ & \\
\hline $10-26-73$ & & $25 \#$ & \\
\hline \multicolumn{4}{|c|}{ 10-29-73 Tower not operating } \\
\hline $11-2-73$ & & $35 \#$ & \\
\hline
\end{tabular}




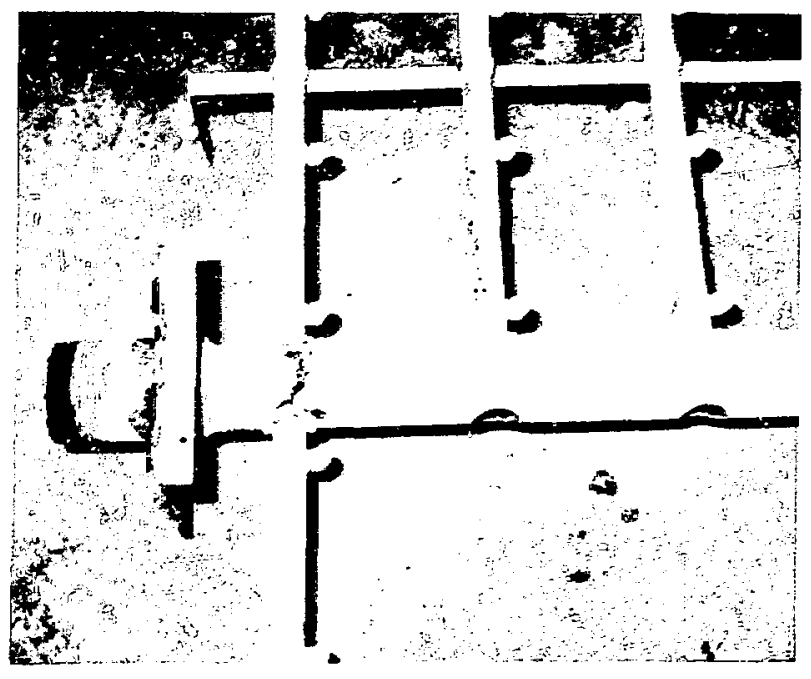

Fig. 1.

Header.

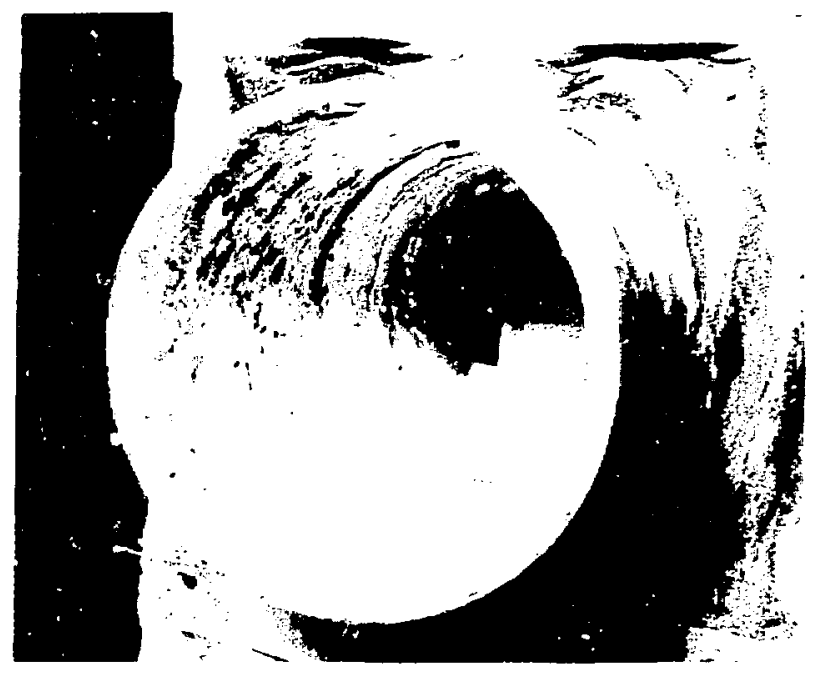

Fig. 3.

Nipple.

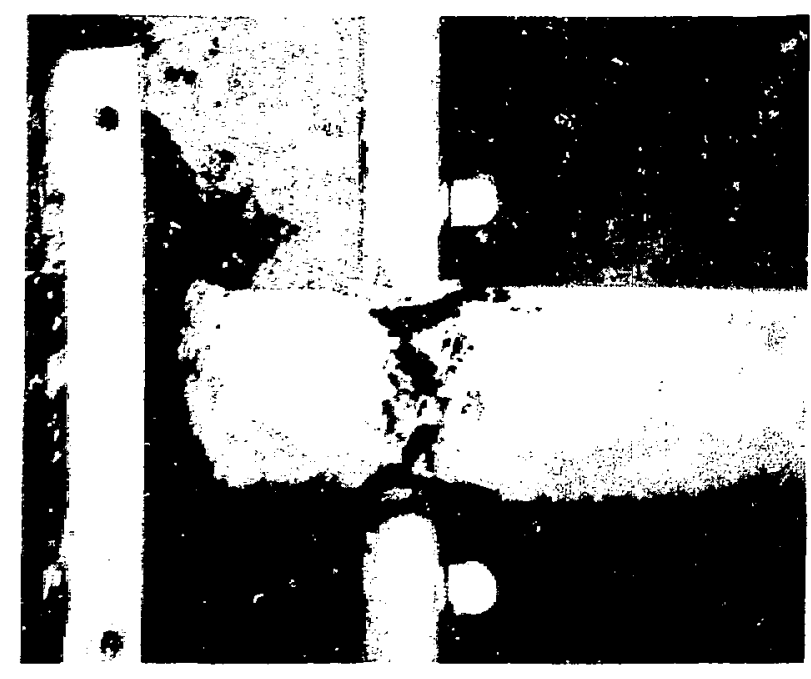

Fig. 2.

Header, close-up.
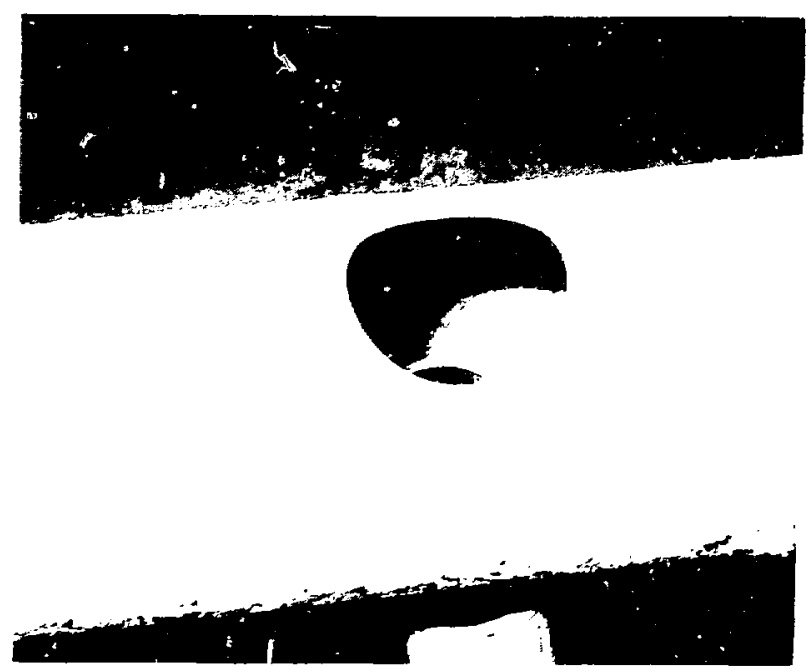

Fig. 4.

Sprayer port. 


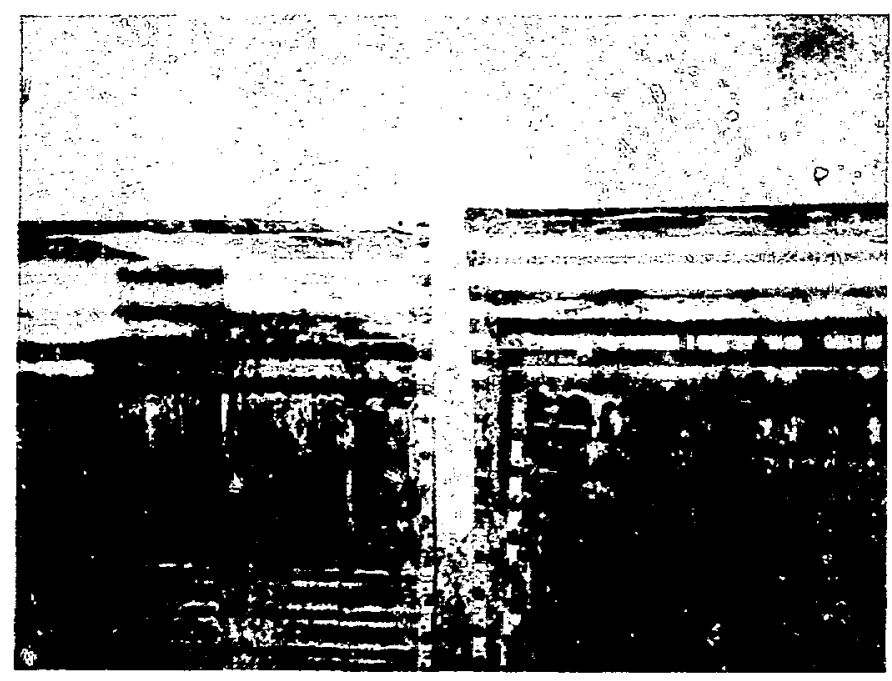

Fig. 5.

Outer panels.

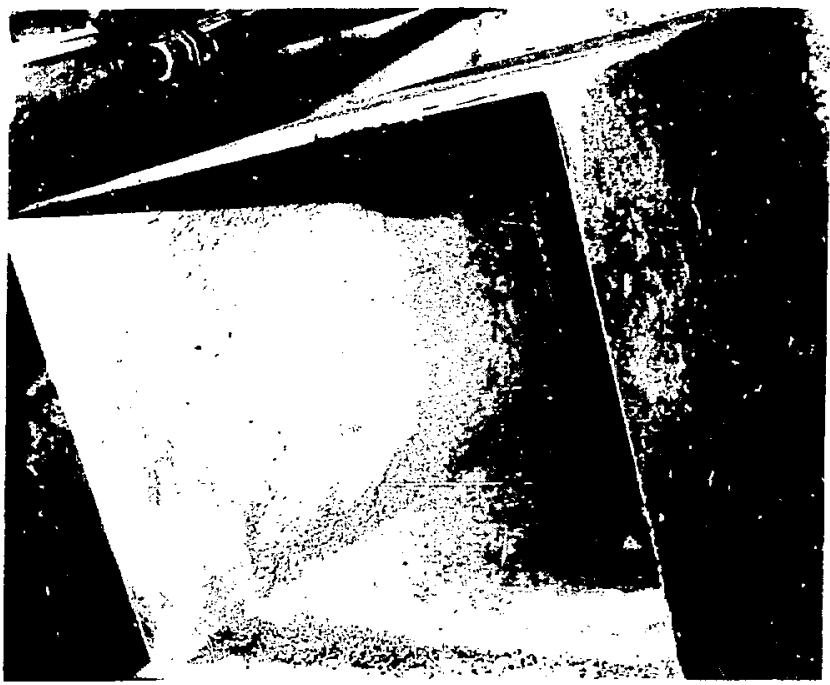

Fig. 6.

Blower duct, left.

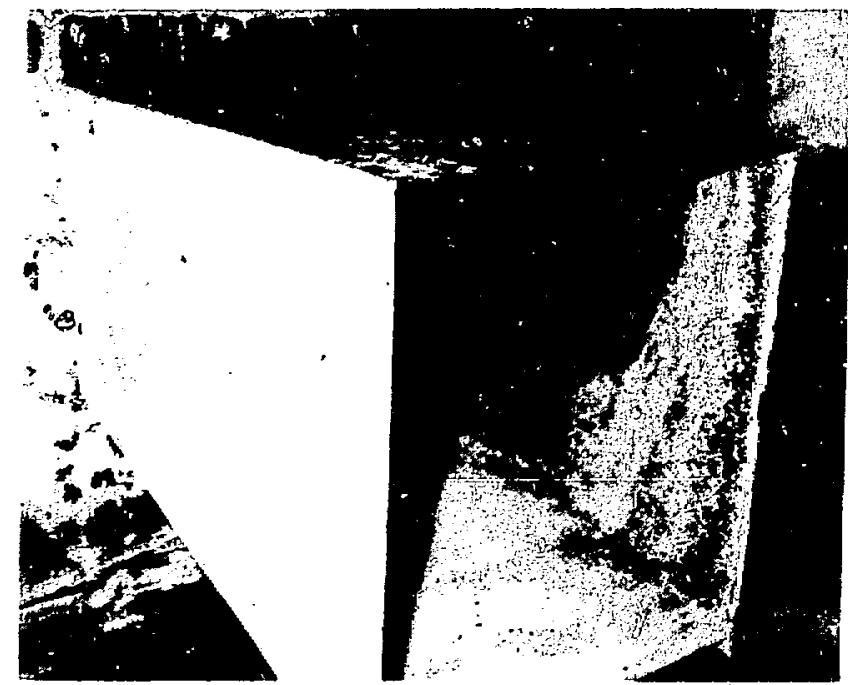

Fig. 7.

Blower duct, rigbt. 


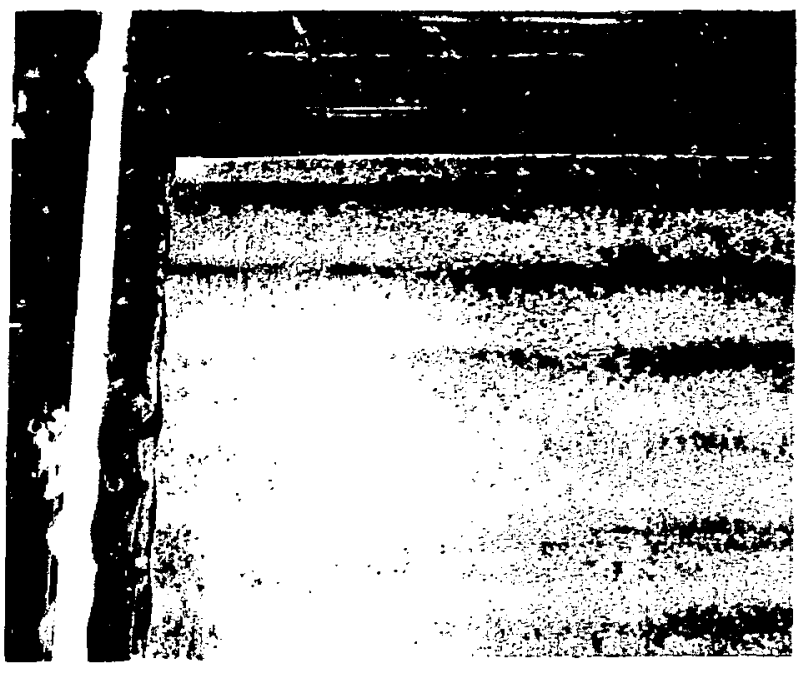

Fig. 8.

Fill, left.

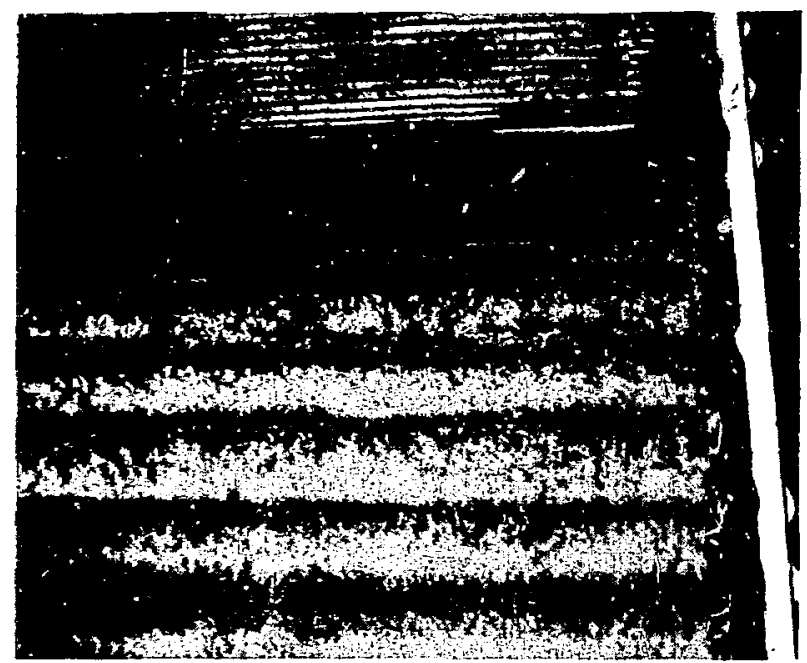

Fig. 9.

Fill, right 